\title{
Global impacts of the automotive supply chain disruption following the Japanese earthquake of 2011
}

\author{
Iñaki Arto, Valeria Andreoni \& Jose Manuel Rueda Cantuche
}

\begin{abstract}
This paper provides an input-output method to estimate worldwide economic impacts generated by supply chain disruptions. The method is used to analyse global economic effects due to the disruptions in the automotive industry that followed the Japanese earthquake and the consequent tsunami and nuclear crisis of March 2011. By combining a mixed multi-regional input-output model, the World Input-Output Database (WIOD) and data at the factory level, the study quantifies the economic impacts of the disruptions broken down by country and industry. The results show that the global economic effect (in terms of value added) of this disruption amounted to US\$139 billion. The most affected (groups of) countries were Japan (39\%), the United States (25\%), China (8\%) and the European Union (7\%). The most strongly affected industries were transport equipment (37\%), other business activities (10\%), basic and fabricated metals (8\%), wholesale trade (7\%), and financial intermediation (4\%).
\end{abstract}

Keywords: Natural disasters; Transport equipment industry; Supply-chain disruptions; Multiregional input-output tables; Japan 


\section{Introduction}

The earthquake measuring nine degrees on the Richter scale that struck Japan on the $11^{\text {th }}$ March 2011, the tsunami that followed and the subsequent nuclear crisis significantly affected the Japanese and global economies. The Cabinet Office of Japan estimated that rebuilding of infrastructure, housing and other Japanese facilities ravaged by the earthquake and tsunami will cost around $¥ 16.9$ trillion (US\$210 billion, 3.8\% of Japan’s GDP). This amount does not include the damage from the nuclear crisis (Ranghieri and Ishiwatari, 2012). In addition, the structural damage coupled with electricity shortages reduced Japanese production capacities, affecting the international production chain and extending the economic impacts largely beyond the national borders.

The impacts of natural disasters on manufacturing industries may result in a production bottleneck affecting other sectors and countries via the reduction in the demand for intermediate inputs or by the reduction in the supply of intermediate outputs (Okuyama and Sahin, 2009). This was the case for the Japanese transport equipment industry (TEI) in the aftermath of the earthquake. According to the data provided by the Japanese Ministry of Economy, Trade and Industry, the production of the Japanese TEI decreased by 50\% between February 2011 and April 2011, thus generating reactions worldwide. The impacts due to the disruption of the supply chain of key components produced by the Japanese TEI were especially relevant in this case. On the one hand, Japan holds a strategic and leadership role in the global TEI, especially as a supplier of key parts for motor vehicle factories located worldwide. Some of these components are very specific and cannot be supplied by any other company in the short term. On the other hand, the automotive industry is characterized by the just-in-time production strategy, aimed at reducing inventory costs by lowering stocks of components. Thus, the possibility of using inventories to overcome supply disruptions was rather limited. As a consequence, the reduction in Japanese exports of key components for the automotive industry generated drops in the global production of vehicles; for example, Toyota, Honda, Opel, Nissan and General Motors froze their production immediately after the earthquake, with losses of US\$72 million a day (Autonews, 2011). According to IHS Global Insight, a global consulting firm, around 2.8 million vehicles (equivalent to $4.7 \%$ of world car production in 2010) were foreseen for production but were in fact not produced. 1 million of these vehicles should have been produced outside Japan (Robinet, 2011).

The impact of the disruption on the supply chain was transmitted to other upstream industries connected to the TEI, such as the production of basic metals, fabricated metals and 
rubbers and plastics. This domino effect spread rapidly around the world, highlighting the vulnerability of the global economy to supply disruptions due to natural disasters.

The complex and increasing connections that currently exists among countries and production chains make it difficult to quantify the global impacts generated by unexpected events. The lack of up-to-date international databases able to capture the trade relationships between countries and sectors, and the consequent limited use of multi-regional models have so far made it very difficult to carry out any kind of estimation of the cascading effects resulting from disruptions in the international supply-demand chain. For this reason, most of the studies published on the economy-wide impacts of the Japanese disaster only account for the impacts in Japan (e.g. Kajitani et al., 2013). Thus, large uncertainties still exist in the quantification of its worldwide economic effect.

In an increasingly interconnected world, however, the quantification of the global economic impacts of unexpected local events and the identification of how they transfer to other regions become of primary importance in order to reduce the vulnerability of modern economies to natural disasters. In particular, the increasing frequency and magnitude of natural disasters and extreme events, generated by global warming and environmental stress, make risk management and recovery strategies a priority both at national and international level (Mirza, 2003). For these reasons, there is an urgent need for multi-regional models and databases able to include a fully-fledged description of international trade and supply chains.

In this paper, a mixed multi-regional input-output model (MRIO), the EU-funded World Input-Output Database (WIOD) and data at the factory level are used to quantify the worldwide economic impacts generated by the disruption in the international supply chain of the TEI generated by the Japanese disaster of March 2011. The paper is structured as follows: Section 2 describes the mixed MRIO model used in this paper and the data sources, Section 3 presents the results and Section 4 covers the discussion.

\section{Methodology and data}

\subsection{Methodology}

A vast variety of input-output (IO) models have been used to estimate the economic impacts generated by unexpected events such as disasters or natural catastrophes (Okuyama et al., 1999, 2004; Okuyama, 2004, 2010; Santos and Haimes, 2004; Veen and Logtmeijer, 2005; Hallegatte, 2008; Rose and Wei, 2013; Okuyama and Santos, 2014), energy constraints (Kerschner et al., 
2009; Arbex and Perobelli, 2010) or financial crises (Yuan et al., 2010). Moreover, a plurality of IO risk-based models, for example the inoperability input-output model (IIM) and its derivative (DIIM), has also been used to analyse the recovery of sectors and evaluate risk management strategies (Haimes and Jiang, 2001; Jiang and Haimes, 2004; Santos and Haimes, 2004; Lian and Haimes, 2006; Barker and Santos, 2010). However, although some of these studies have estimated the inter-regional impacts of disasters ( Okuyama et al., 1999; Yamano et al., 2007; Okuyama, 2010; Jonkeren and Giannopoulos, 2014), most of them have a single country/regional perspective and do not include the intra-country/regional impacts produced by the existing links through international trade. Moreover, despite the increasing number of international supply chain disruptions due to major natural disasters (e.g. the 2011 Japanese earthquake or the Thai floods of 2011) limited empirical evidence on their global effects is available (Leckcivilize, 2013).

One of the reasons for the lack of interregional analyses might have been the absence of publicly available and up-to-date MRIO databases. As mentioned before, the EU-funded project World Input Output Database (WIOD) (Dietzenbacher et al., 2013) has now largely filled this gap and opens the door for the use of MRIO models for estimating worldwide economic impacts of unexpected events.

The MRIO model used in this study is a mixed IO model in which the exogenous shocks can be either final demand changes or changes in gross output levels (see Miller and Blair, 2009 , pp. 621-633, for a detailed description of this type of models). These models have often been applied in empirical studies to analyse the economy-wide effects of a reduction in the demand for intermediate inputs due to constraints in the output of a sector (Steinback, 2004). In this study, we extend the scope of the standard mixed MRIO to also calculate the impacts due to the reduction in the intermediate outputs (i.e. disruptions in the supply chain) resulting from a constraint in the output of a sector.

First, we show the standard formulation of the mixed MRIO model for capturing the impacts in the different sectors of the economy resulting from the reduction on the intermediate demand of a sector derived from a constraint in its output after an external shock. Second, we explain how to calculate the impacts derived from the disruption in the supply chain of a sector by combining the mixed MRIO model with information on the first round impact on the sectors directly affected by the disruption on the supply chain.

\subsubsection{Standard mixed MRIO model}


In order to summarize the standard mixed MRIO model used in this paper, an explanatory case is presented for two regions $(\mathrm{R}, \mathrm{S})$ with two sectors $(1,2)$ producing goods that can be sold as intermediate inputs or as final products. Since both regions are opened to external trade, their domestic production can be consumed within the region and/or abroad. The relationships between the production and the consumption activities in the two regions can be expressed as depicted in Figure 1, where the element $z_{i j}^{R S}$ of matrix $\mathbf{Z}^{\mathrm{RS}}$ indicates the intermediate use by sector $j$ of region $\mathrm{S}$ of goods produced by sector $i$ of region $\mathrm{R}$; the element $y_{i}^{R S}$ of the vector $\mathbf{y}^{\mathbf{R S}}$ denotes the final demand of region $\mathrm{S}$ for goods produced by sector $i$ of region $\mathrm{R}$; the element $x_{i}^{R}$ of vector $\mathbf{x}^{\mathbf{R}}$ is the total output of sector $i$ in region $\mathrm{R}$; and the element $w_{i}^{R}$ of vector $\mathbf{w}^{\mathbf{R}}$ is the value added of sector $i$ in region $\mathrm{R}$.

\section{***INSERT Figure 1 ABOUT HERE***}

Figure 1 can be expressed as a system of equations, which reads in matrix notation as follows:

$$
\left[\begin{array}{l}
x^{R} \\
x^{S}
\end{array}\right]=\left[\begin{array}{ll}
Z^{R R} & Z^{R S} \\
Z^{S R} & Z^{S S}
\end{array}\right]\left[\begin{array}{l}
e \\
e
\end{array}\right]+\left[\begin{array}{l}
y^{R R}+y^{R S} \\
y^{S R}+y^{S S}
\end{array}\right]
$$

where $\mathbf{e}$ is a column vector of ones for summation.

The input coefficients are obtained from $\mathbf{A}^{\mathbf{R S}}=\mathbf{Z}^{\mathbf{R S}}\left(\hat{\mathbf{x}}^{\mathbf{s}}\right)^{-1}$, where $a_{i j}^{R S}$ of matrix $\mathbf{A}^{\mathbf{R S}}$ indicates the quantity of output from sector $i$ of region $\mathrm{R}$ used by sector $j$ of region $\mathrm{S}$ to produce one unit of output. Now, we rewrite equation [1] as

$$
\left[\begin{array}{l}
x^{R} \\
x^{S}
\end{array}\right]=\left[\begin{array}{ll}
A^{R R} & A^{R S} \\
A^{S R} & A^{S S}
\end{array}\right]\left[\begin{array}{l}
x^{R} \\
x^{S}
\end{array}\right]+\left[\begin{array}{l}
y^{R R}+y^{R S} \\
y^{S R}+y^{S S}
\end{array}\right]
$$

Reordering expression [2] yields:

$$
\left[\begin{array}{cc}
I-A^{R R} & -A^{R S} \\
-A^{S R} & I-A^{S S}
\end{array}\right]\left[\begin{array}{l}
x^{R} \\
x^{S}
\end{array}\right]=\left[\begin{array}{l}
y^{R R}+y^{R S} \\
y^{S R}+y^{S S}
\end{array}\right]
$$


and considering, as in standard IO analysis, the total output as endogenous and final demand as exogenous, equation [3] can be expressed as:

$$
\left[\begin{array}{c}
x_{1}^{R} \\
x_{2}^{R} \\
x_{1}^{S} \\
x_{2}^{S}
\end{array}\right]=\left[\begin{array}{cccc}
\left(1-a_{11}^{R R}\right) & -a_{12}^{R R} & -a_{11}^{R S} & -a_{12}^{R S} \\
-a_{21}^{R R} & \left(1-a_{22}^{R R}\right) & -a_{21}^{R S} & -a_{21}^{R S} \\
-a_{11}^{S R} & -a_{12}^{S R} & \left(1-a_{11}^{S S}\right) & -a_{12}^{S S} \\
-a_{21}^{S R} & -a_{22}^{S R} & -a_{21}^{S S} & \left(1-a_{22}^{S S}\right)
\end{array}\right]^{-1}\left[\begin{array}{c}
y_{1}^{R R}+y_{1}^{R S} \\
y_{2}^{R R}+y_{2}^{R S} \\
y_{1}^{S R}+y_{1}^{S S} \\
y_{2}^{S R}+y_{2}^{S S}
\end{array}\right]
$$

which can also be expressed as

$$
\mathbf{x}=\mathbf{L y}
$$

where $\mathbf{L}$ is the Leontief inverse matrix.

Let us assume that we want to analyse the effects of an external shock constraining the production capacity of sector 2 in region S. The initial impact of the shock would be the reduction in the total output of sector 2 in region $S$ (the initial effect in Figure 2). This would reduce the demand for products from the sectors directly supplying intermediate inputs to the constrained sector (the backward direct effect in Figure 2). Finally, the impact would affect the sectors indirectly involved in the supply chain of the constrained sector (the backward indirect effect in Figure 2).

\section{***INSERT Figure 2 ABOUT HERE***}

In such a case, the total output of sector 2 of region $\mathrm{S}$ would become exogenous, while its final demand would be endogenous. The assumptions on the remaining outputs and final demands of the other sectors remain unchanged. Next, rearranging equation [4] so as to leave the exogenous variables on the right-hand side and the endogenous variables on the left-hand side, we obtain: 
$\left[\begin{array}{cccc}\left(1-a_{11}^{R R}\right) & -a_{12}^{R R} & -a_{11}^{R S} & 0 \\ -a_{21}^{R R} & \left(1-a_{22}^{R R}\right) & -a_{21}^{R S} & 0 \\ -a_{11}^{S R} & -a_{12}^{S R} & \left(1-a_{11}^{S S}\right) & 0 \\ -a_{21}^{S R} & -a_{22}^{S R} & -a_{21}^{S S} & -1\end{array}\right]\left[\begin{array}{c}x_{1}^{R} \\ x_{2}^{R} \\ x_{1}^{S} \\ y_{2}^{S R}+y_{2}^{S S}\end{array}\right]=\left[\begin{array}{cccc}1 & 0 & 0 & a_{12}^{R S} \\ 0 & 1 & 0 & a_{22}^{R S} \\ 0 & 0 & 1 & a_{12}^{S S} \\ 0 & 0 & 0 & -\left(1-a_{22}^{S S}\right)\end{array}\right]\left[\begin{array}{c}y_{1}^{R R}+y_{1}^{R S} \\ y_{2}^{R R}+y_{2}^{R S} \\ y_{1}^{S R}+y_{1}^{S S} \\ x_{2}^{S}\end{array}\right]$

Finally, by rearranging terms in equation [5] we find:

$$
\left[\begin{array}{c}
x_{1}^{R} \\
x_{2}^{R} \\
x_{1}^{S} \\
y_{2}^{S R}+y_{2}^{S S}
\end{array}\right]=\left[\begin{array}{cccc}
\left(1-a_{11}^{R R}\right) & -a_{12}^{R R} & -a_{11}^{R S} & 0 \\
-a_{21}^{R R} & \left(1-a_{22}^{R R}\right) & -a_{21}^{R S} & 0 \\
-a_{11}^{S R} & -a_{12}^{S R} & \left(1-a_{11}^{S S}\right) & 0 \\
-a_{21}^{S R} & -a_{22}^{S R} & -a_{21}^{S S} & -1
\end{array}\right]^{-1}\left[\begin{array}{cccc}
1 & 0 & 0 & a_{12}^{R S} \\
0 & 1 & 0 & a_{22}^{R S} \\
0 & 0 & 1 & a_{12}^{S S} \\
0 & 0 & 0 & -\left(1-a_{22}^{S S}\right)
\end{array}\right]\left[\begin{array}{c}
y_{1}^{R R}+y_{1}^{R S} \\
y_{2}^{R R}+y_{2}^{R S} \\
y_{1}^{S R}+y_{1}^{S S} \\
x_{2}^{S}
\end{array}\right]
$$

which can also be expressed as

$$
\left[\begin{array}{c}
\mathbf{x}_{\mathrm{no}} \\
y_{2}^{S}
\end{array}\right]=\mathbf{M}^{-1} \mathbf{N}\left[\begin{array}{c}
\mathbf{y}_{\mathbf{n o}} \\
x_{2}^{S}
\end{array}\right]
$$

where $\mathbf{X}_{\text {no }}$ represents the endogenous total output of the non-constrained sectors 1 and 2 in region $\mathrm{R}$ and the endogenous total output of sector 1 in region $\mathrm{S} ; y_{2}^{S}$ stands for the endogenous total final demand of regions $\mathrm{R}$ and $\mathrm{S}$ of the constrained sector (i.e. sector 2 in region $\mathrm{S}$ ); $x_{2}^{S}$ indicates the exogenous total output of the constrained sector (sector 2 in region $\mathrm{S}$ ); and $\mathbf{y}$ o depicts the exogenous final demand of regions $\mathrm{R}$ and $\mathrm{S}$ for the goods produced by sectors 1 and 2 in region $\mathrm{R}$, as well as that of sector 1 in region $\mathrm{S}$.

Following Miller and Blair (2009, pp. 623-624) and using results on partitioned matrix inverses, it can be shown that:

$$
\mathbf{M}^{-1}=\left[\begin{array}{cccc}
l_{11}^{R R(3)} & l_{12}^{R R(3)} & l_{11}^{R S(3)} & 0 \\
l_{21}^{R R(3)} & l_{22}^{R R(3)} & l_{21}^{R S(3)} & 0 \\
l_{11}^{S R(3)} & l_{12}^{S R(3)} & l_{11}^{S S(3)} & 0 \\
b_{1} & b_{2} & b_{3} & -1
\end{array}\right]
$$


where

$\mathbf{L}^{(3)}=\left[\begin{array}{lll}l_{11}^{R R(3)} & l_{12}^{R R(3)} & l_{11}^{R S(3)} \\ l_{21}^{R R(3)} & l_{22}^{R R(3)} & l_{21}^{R S(3)} \\ l_{11}^{S R(3)} & l_{12}^{S R(3)} & l_{11}^{S S(3)}\end{array}\right]$

is the Leontief inverse for a model consisting of the three non-constrained sectors. ${ }^{1}$ From [6] and [7], it follows that the output of the non-constrained sectors is given by

$\left[\begin{array}{l}x_{1}^{R} \\ x_{2}^{R} \\ x_{1}^{S}\end{array}\right]=\left[\begin{array}{lll}l_{11}^{R R(3)} & l_{12}^{R R(3)} & l_{11}^{R S(3)} \\ l_{21}^{R R(3)} & l_{22}^{R R(3)} & l_{21}^{R S(3)} \\ l_{11}^{S R(3)} & l_{12}^{S R(3)} & l_{11}^{S S(3)}\end{array}\right]\left[\begin{array}{c}y_{1}^{R R}+y_{1}^{R S}+a_{12}^{R S} \\ y_{2}^{R R}+y_{2}^{R S}+a_{22}^{R S} \\ y_{1}^{S R}+y_{1}^{S S}+a_{12}^{S S}\end{array}\right] x_{c o}^{S}$

Equation [8] determines the output of the non-constrained sectors in R and S, on the basis of the output of the supply-constrained sector (i.e. sector 2 of region S) and the total final demand for goods produced by non-constrained sectors. ${ }^{2}$

We can apply this model to the case of a reduction in the output of the constrained sector $\left(\Delta x_{2}^{S}<0\right)$, with the final demand of the non-constrained sectors remaining constant $\left(\Delta \mathbf{y}_{\text {no }}=0\right.$ ). In such a case, it follows from [8] that the reduction in the output of the non-constrained sectors will be

$$
\left[\begin{array}{c}
\Delta x_{1}^{R} \\
\Delta x_{2}^{R} \\
\Delta x_{1}^{S}
\end{array}\right]=\left[\begin{array}{lll}
l_{11}^{R R(3)} & l_{12}^{R R(3)} & l_{11}^{R S(3)} \\
l_{21}^{R R(3)} & l_{22}^{R R(3)} & l_{21}^{R S(3)} \\
l_{11}^{S R(3)} & l_{12}^{S R(3)} & l_{11}^{S S(3)}
\end{array}\right]\left[\begin{array}{c}
a_{12}^{R S} \\
a_{22}^{R S} \\
a_{12}^{S S}
\end{array}\right] \Delta x_{c o}^{S}
$$

which can also be expressed as

\footnotetext{
${ }^{1}$ The exact values of $b_{1}, b_{2}$ and $b_{3}$ are not relevant for our analysis.

${ }^{2}$ These equations can be generalized to a context with $m$ sectors and $n$ countries. Moreover, the number of supplyconstrained sectors can also be expanded.
} 


$$
\Delta \mathbf{x}_{\mathrm{no}}=\mathbf{L}^{(3)} \mathbf{a}_{\mathrm{co}} \Delta x_{2}^{S}
$$

The vector $\mathbf{a}_{\text {co }} \Delta x_{2}^{S}$ of equation [9] translates the reduction in the output of the constrained sector into changes in its demand for inputs from non-constrained sectors, and the inverse of the nonconstrained sectors converts input demand into total necessary gross output from those sectors. In other words, equation [9] computes the direct and indirect backward impacts in terms of changes in the output of the non-constrained sectors due to changes in the intermediate demands of the constrained sector. For instance, applying this model to the assessment of the effects of the reduction of the TEI's output in Japan, we would obtain the direct and indirect reduction in the output of all the sectors involved in supplying intermediates to the Japanese TEI.

In addition, we can also calculate the effects in terms of value added. For that purpose, we define the value added coefficients as $\mathbf{v}=\mathbf{w}^{\prime}(\hat{\mathbf{x}})^{-1}$. Thus, the backward impact in the value added of the non-constrained sectors due to a shock in the output of the constrained sectors will be given by the following expression:

$$
\Delta \mathbf{w}_{\text {no }}=\hat{\mathbf{v}}_{\mathrm{no}} \mathbf{L}^{(3)} \mathbf{a}_{\mathrm{co}} \Delta x_{2}^{S}
$$

This backward impact can be split into two components:

- Standard backward direct impact $\hat{\mathbf{v}}_{\text {no }} \mathbf{a}_{\text {co }} \Delta x_{2}^{S}$, which captures the change in the value added of the non-constrained sectors supplying inputs directly to the sector impacted by the shock;

- Standard backward indirect impact $\hat{\mathrm{v}}_{\text {no }} \mathbf{L}^{(3)} \mathbf{a}_{\text {co }} \Delta x_{2}^{S}-\hat{\mathrm{v}}_{\mathrm{no}} \mathbf{a}_{\mathrm{co}} \Delta x_{2}^{S}$, which denotes the change in the value added of other non-constrained sectors indirectly involved in the supply chain of the sector impacted by the shock.

Finally, as in the case of the standard MRIO model, we could also complete this information with the initial impact $v_{2}^{S} \Delta x_{2}^{S}$, which computes the change in the value added of the sector directly impacted by the shock.

This model can be used to capture the backward effects due to a reduction in the intermediate demand of a sector resulting from a reduction in its output. However, it fails to 
compute the impacts resulting from the reduction in the intermediate outputs supplied to other sectors and the subsequent cascading effects. ${ }^{3}$

\subsubsection{Mixed MRIO model with information on the first round impacts of the disruption on the supply chain}

The standard mixed MRIO model represented by expression [6] is valid for calculating the backward effects derived from a constraint in the output of a sector. However, it does not compute the effects resulting from the reduction in the intermediate outputs delivered to other sectors and the subsequent indirect effects. For instance, it would not include the reduction in the output of the non-Japanese TEI companies using components produced in Japan (supply chain disruption initial effect in Figure 3) and the subsequent impacts in the sectors directly and indirectly involved in the supply chain of the non-Japanese TEI (supply chain disruption backward direct and indirect effects in Figure 3).

Moreover, it is well-known that in IO models sectors and products are treated as homogenous (each sector produces one single commodity) and that there is no substitution between inputs. Accordingly, the impacts of the reduction in the exports of a constrained sector would be the same in all the importing companies of a sector regardless of the product actually imported. However, this assumption does not work in the real world, especially in some specific sectors such as the TEI, in which the impacts will be highly dependent on which component is in short supply and to what extent it can be substituted. In the case of the disruption of the supply chain of the TEI following the Japanese disaster, there is evidence that the impact was limited to some specific factories that were using specific Japanese components (see Robinet, 2011).

\section{***INSERT Figure 3 ABOUT HERE***}

Nevertheless, these shortcomings of IO models do not mean that they cannot be used to assess the effects of disruptions of supply chains. In order to overcome the abovementioned limitations, we suggest exogenizing the output of those sectors downstream directly affected by the disruption of the supply chain. The underlying idea to this approach is to incorporate real

\footnotetext{
${ }^{3}$ Note that these cascading effects refer to impacts due the reduction in the intermediate inputs of the sectors affected due to the disruption of the supply chain and, therefore, can also be considered as backward impacts.
} 
data on the first round effects in non-Japanese TEI due to the supply chain disruption into the analysis to compute the subsequent backward impacts in all the other sectors involved in the supply chain of the non-Japanese TEI. ${ }^{4}$ This approach ensures that the first round downstream effects of the shock matches real data and, consequently, the indirect effects are calculated with a higher degree of accuracy. In addition, as the changes in the output of the transport equipment sector match the real data, the possibility of substitution of Japanese inputs is, to some extent, implicitly taken into account. For example, if the disrupted Japanese components were supplied by other countries, the production of the factories using those inputs and the rest of their suppliers would not be affected. The use of actual production data would allow these substitution effects to be captured because they record the net reduction in the output. However, in order to estimate the positive impacts in the new suppliers, further information would be needed.

The implementation of this approach for the calculation of the impacts due to the disruption of the supply chain in our two-region - two-sector model implies treating the output of sector 2 in regions $\mathrm{R}$ as an exogenous variable. The shock in the output of sector 2 in region $\mathrm{R}$ would capture the first round downstream effect on the same sector of the other country directly affected by the disruption (non-Japanese TEI using components of the Japanese TEI). Thus, the change in the value added of the non-constrained sectors due to a shock in the output of the constrained sectors will be given by:

$$
\left[\begin{array}{l}
\Delta x_{1}^{S} \\
\Delta x_{2}^{S} \\
\Delta x_{1}^{R}
\end{array}\right]=\left[\begin{array}{lll}
k_{11}^{S S(3)} & k_{12}^{S S(3)} & k_{11}^{S R(3)} \\
k_{21}^{S S(3)} & k_{22}^{S S(3)} & k_{21}^{S R(3)} \\
k_{11}^{R S(3)} & k_{12}^{R S(3)} & k_{11}^{R R(3)}
\end{array}\right]\left[\begin{array}{c}
a_{12}^{S R} \\
a_{22}^{S R} \\
a_{12}^{R R}
\end{array}\right] \Delta x_{c o}^{R}
$$

which can be expressed as

$$
\Delta \mathbf{w}_{\mathrm{no}}=\hat{\mathbf{v}}_{\mathrm{no}} \mathbf{K}^{(3)} \mathbf{a}_{\mathrm{co}} \Delta x_{2}^{R}
$$

\footnotetext{
${ }^{4}$ Note that this assumption ignores the effects of the supply chain disruption on other sectors different than the TEI. However, as we show in the discussion this impact can be considered negligible.
} 
where the elements of $\mathbf{K}^{(3)}$ are derived similarly to those of $\mathbf{L}^{(3)}$.

Thus, this approach will enable to capture the impacts due to the disruption of the supply chain and the subsequent constraint in the output of sector 2 of region $\mathrm{R}$ (see Figure 3 ). These impacts can be decomposed into three types:

- Supply chain disruption initial (SCD-I) impact, $v_{2}^{R} \Delta x_{2}^{R}$, is the change in the value added of the sector directly affected by the disruption in its supply chain;

- Supply chain disruption backward direct (SCD-BD) impact, $\hat{\mathrm{v}}_{\mathrm{no}} \mathbf{a}_{\mathrm{co}}^{\mathbf{R}} \Delta x_{2}^{R}$, is the change in the value added of the non-constrained sectors supplying inputs directly to the sector directly affected by the disruption in its supply chain;

- Supply chain disruption backward direct (SCD-BI) impact, $\hat{\mathrm{v}}_{\mathrm{no}} \mathbf{K}^{(3)} \mathbf{a}_{\mathrm{co}}^{\mathbf{R}} \Delta x_{2}^{R}-\hat{\mathrm{v}}_{\mathrm{no}} \mathbf{a}_{\mathrm{co}}^{\mathbf{R}} \Delta x_{2}^{R}$, is the value added of other non-constrained sectors indirectly involved in the supply chain of the sector affected by the disruption. ${ }^{5}$

\subsection{Data}

We have used equations [10] and [11] to explore the effects of a reduction in the output of the TEI after the Japanese disaster of 2011, and the subsequent (standard) backward effect and supply chain disruption effect.

The data used to build the MRIO model have been obtained from the symmetric world input-output table (WIOT) of the year 2010 (i.e. the year before the earthquake) of the WIOD database (Dietzenbacher et al., 2013). This table covers 35 industries and 41 countries (27 EU countries, 13 non-EU countries and the Rest of the World as an aggregated region). The mixed MRIO model has been structured following the sector and country specifications of the WIOT (i.e. 35 sectors and 41 regions).

In addition, in order to run the model, information on the reduction of the output of the TEI (exogenous variables) is needed. One data source could be the change in the industrial production reported by national statistical institutes. However, these data do not show the extent to which the change in production levels is the consequence of the shock on the TEI.

The option that we have used consists of using micro data on the actual impact of the shock. Just a few months after the Japanese disaster, some reports were published assessing the

\footnotetext{
${ }^{5}$ Note that the SCD-BD and SCD-BI also include the backward impacts on the sector that originally suffered the shock. This allow us to compute the impact in the Japanese TEI companies supplying components to the nonJapanese TEI that are indirectly affected by the disruption on the supply of key components produced by other Japanese TEI companies.
} 
detailed impacts of the disruption on the supply chain in the car industry all over the world. In June 2011, (Robinet, 2011) quantified the reduction in the production of Light Vehicles (LV), including passenger cars and light commercial vans, due to the disruption in the supply chain after the Japanese disaster for 129 facilities around the world between $11^{\text {th }}$ March and $3^{\text {rd }}$ June 2011. ${ }^{6}$ Starting with these data, we have aggregated those reductions by facility at the country level ( $2^{\text {nd }}$ column of Table 1$)$ and we have divided these figures by the total LV production of the year 2010 from the International Organization of Motor Vehicle Manufacturers (OICA, 2012) ( $4^{\text {th }}$ column of Table 1$)$, obtaining the change in the production of LV due to the Japanese disaster $\left(5^{\text {th }}\right.$ column of Table 1$)$. Finally, for each country, we have calculated the reduction in the total output of the TEI assuming that the reduction in the output of the whole TEI was equal to that of the LV industry $\left(6^{\text {th }}\right.$ column of Table 1$) .^{7}$

In order to compute the impacts due to the disruption on the intermediate demand of the Japanese TEI, we have taken the reduction in the output of the Japanese TEI as exogenous. This would be represented by the term $\Delta x_{c o}^{S}$ in equation [10]. On the other hand, in order to overcome the limitations of the mixed MRIO model for capturing the impacts of the disruption of the supply chain, we have also taken the actual reduction in the output of the TEI that was registered in other countries as exogenous. This would be represented by the term $\Delta x_{2}^{R}$ in equation [11], but now the number of constrained sectors includes all the other countries in which the output of the TEI was affected by the disruption in the supply chain (see $5^{\text {th }}$ column of Table 1 ).

***INSERT Table 1 ABOUT HERE***

\section{Results}

As a consequence of the catastrophic events that struck Japan in March 2011, the Japanese TEI reduced its output by $4.7 \%$ (column 7 of Table 1), causing a reduction in the value added of that sector of US\$25 billion (column 2 of Table 2). This event also had consequences for the different steps of the supply chain of the TEI all over the world, generating additional losses of

\footnotetext{
${ }^{6}$ (Robinet, 2011) reports detailed data until $3^{\text {rd }}$ June 2011. This data has been up-scaled to match the total cumulative losses estimated by the author until September 2011.

${ }^{7}$ The figures showed in column (6) of Table 2 constitute the exogenous shocks applied to equation [10].
} 
US\$114 billion (Table 2, columns 3 to 7). Thus, the total reduction in the global value added totaled US $\$ 139$ billion (Table 2, column 8), equivalent to $0.23 \%$ of world's value added in 2010 .

***INSERT Table 2 ABOUT HERE***

All the regions analyzed suffered negative effects in terms of value added. In particular, Japan absorbed $39.5 \%$ of the total impact, with a reduction of the value added of US\$54.9 billion (1\%). Excluding Japan, the United States was the country with the largest reduction in value added (US $\$ 35.1$ billion and $25.2 \%$ of total losses). China was also seriously affected by the disruption in the supply-production chain, with an aggregated reduction in the total value added of US $\$ 11.1$ billion ( $8 \%$ of the total losses). It is also worth pointing out the reduction in the value added of the EU (US\$10.4 billion) and Canada (US\$10.1 billion). Within the EU, the United Kingdom (US\$4.3 billion), Germany (US\$1.5 billion) and France (US\$1.5 billion) were the countries with the largest value added losses. In relative terms, apart from Japan, Canada suffered the largest drop in the value added (-0.69\%), followed by Indonesia $(-0.4 \%)$, the United States (-0.24\%), the United Kingdom (-0.21\%), Australia (-0.18\%), China (-0.18\%), Mexico ($0.16 \%)$ and Taiwan $(-0.16 \%)$.

Columns 3 to 7 of Table 2 show the impacts on the value added of the different countries according to the step of the supply chain in which they were generated. On the one hand, many companies supplying components directly to the Japanese TEI were forced to stop their production processes, with losses in terms of value added of US\$24.6 billion (column 3), of which 95\% were generated in Japan. In addition, other sectors indirectly involved in the supply chain of the Japanese TEI faced losses of US\$11.8 billion (column 4), of which $61 \%$ were suffered by non-Japanese countries.

Meanwhile, the reduction in the output of the Japanese TEI and the subsequent disruption in the global supply chain of the sector generated important impacts worldwide. The value added of non-Japanese TEI fell by US $\$ 24.5$ billion (column 5) and the value added of the sectors directly and indirectly supplying components to non-Japanese TEI decreased by US\$30.6 billion and US\$22.7 billion respectively (columns 6 and 7).

Comparing the share of the different effects over the total impact, we can conclude that the impacts of the disruption of the supply chain are the most relevant, with a contribution to the total reduction in the value added of $55.9 \%$, followed by the standard backward $(26.1 \%)$ and initial effects $(17.9 \%)$. 
Table 3 shows the change in the value added broken down by sector. The TEI absorbed most of the reduction in the total value added (36.6\%), followed by renting machinery and equipment services and other business activities (10.1\%), manufacture of basic metals and fabricated metals $(8.2 \%)$, wholesale trade $(7.1 \%)$, and financial intermediation $(4.4 \%)$. These five sectors accounted for two thirds of the total losses. Unsurprisingly, TEI was also the sector with the largest reduction in its value added (-5.5\%) followed by manufacture of basic metals and fabricated metals $(-0.82 \%)$, rubber and plastics $(-0.75 \%)$ and electrical and optical equipment (-0.39\%). All the remaining economic sectors suffered smaller impacts in terms of value added.

\section{***INSERT Table 3 ABOUT HERE***}

\section{Discussion}

This study presents the first attempt to quantify the worldwide economic impacts generated by the disruption of the supply chain of the transport equipment industry (TEI) that followed the Japanese disaster of March 2011. The use of a mixed multi-regional input-output (MRIO) model together with information on the first round downstream effects, and the World InputOutput Database (WIOD), allows the estimation of the cascading effects generated worldwide by the disruption to the TEI's supply chain. These cascading effects include the total backward effects in the sectors and countries providing components to the Japanese TEI, the impact in the non-Japanese TEI affected by the disruption in the intermediate deliveries of key components from the Japanese TEI, and the subsequent cascading effects in all the other sectors supplying components to the non-Japanese TEI. Results show that the initial impact on the value added of the Japanese TEI was US\$24.5 billion. However, when the cascading effects generated in other economic sectors are accounted for, the total reduction in global value added rises to US\$139 billion. Supply chain disruption effects made up more than a half of the reduction in the value added, while the backward impacts and the initial impact in the Japanese TEI accounted for $26.1 \%$ and $17.9 \%$ respectively.

The results also show the relevance of taking the impacts from a global inter-regional perspective into account. Thus, while Japan suffered around $40 \%$ of the total impact, the rest of the world bore almost $60 \%$, with the United States (25\% of total impact), China ( $8 \%$ ), the European Union (8\%), and Canada (7\%) the most impacted regions. The WIOD covers 35 
sectors, and includes only one transport equipment manufacturing industry (which includes the production of many different transport vehicles and parts). Thus, the results derived from the analysis should be interpreted as indications. Nevertheless, the increasing globalization of the international supply-production chain and the large interconnectivity of the different economies certainly contribute to increase the vulnerability of regional economies to any kind of disaster occurring anywhere in the world (Yamano et al., 2007; Barker and Santos, 2010;). Thus, the results of these studies could be useful for decision making in many different areas such as risk management strategies (diversification of suppliers), logistics and production organization strategies (especially inventories management).

Although the model used is suitable for computing the effects of disruptions in the supply chain, it shows some shortcomings. It is able to capture most of the impacts generated by the disruption of the supply chain, but not all. For instance, the impacts generated in other sectors besides the TEI, but using inputs from the TEI sector, would not be captured (e.g. automotive repair and maintenance sector), although these impacts are relatively small compared to the ones already captured by the model (e.g. in the case of Japan, $90 \%$ of the intermediate output of the TEI is used by the Japanese and foreign TEI). In addition, the supply chain effect computed by the model also includes some of the backward effects derived from the reduction in the intermediate demand of the Japanese TEI (i.e. part of the impact in the non-Japanese TEI could be due to the reduction in the demand for intermediates from the Japanese TEI) This would be the case for the non-Japanese TEIs affected by the disruption in the supply chain that are also suppliers of inputs to the Japanese TEI. However, in this case study, the Japanese exports from foreign TEI are 3.5 times higher than the imports and it would be expected that only a fraction of the impact computed as supply chain would actually be backward. Finally, although the model explicitly computes the feedback loops between all the sectors involved in supply chain of the TEI, it does not explicitly capture the feedback loop within the TEI worldwide. However, this effect is implicitly accounted for in the initial effect, which covers the total reduction in the production of the TEI.

In recent years, computable general equilibrium (CGE) models are becoming more popular for disaster impact analysis. Unlike IO models, CGE models are non-linear, can respond to price changes, can accommodate input and import substitutions, and can explicitly handle supply constraints (Okuyama and Santos, 2014). However, these advantages with respect to IO models may turn into disadvantages when assessing the disruption of the supply of key components that, in the very short run, cannot be supplied by any other producer, and therefore, all the adjustments in CGE-models cannot take place completely. In this sense, CGEs 
could be considered too flexible for the assessment of disruption in the supply chain of key components, while the rigidity and simplicity of the mixed MRIO model would represent an advantage in this case.

\section{References}

Arbex, M., Perobelli, F.S., 2010. Solow meets Leontief: Economic growth and energy consumption. Energy Economics, 32, 43-53.

Autonews, F. wire, 2011. Opel, Renault production hit by shortage of Japanese parts http://www.autonews.com/article/20110318/COPY01/303189860/opel-renaultproduction-hit-by-shortage-of-japanese-parts (accessed 8.13.14).

Barker, K., Santos, J.R., 2010. Measuring the efficacy of inventory with a dynamic input-output model. International Journal of Production Economics, 126, 130-143.

Dietzenbacher, E., Los, B., Stehrer, R., Timmer, M., de Vries, G., 2013. The construction of world input-output tables in the WIOD project. Economic Systems Research, 25, 7198.

Haimes, Y., Jiang, P., 2001. Leontief-Based Model of Risk in Complex Interconnected Infrastructures. Journal of Infrastructure Systems, 7, 1-12.

Hallegatte, S., 2008. An adaptive regional input-output model and its application to the assessment of the economic cost of Katrina. Risk Analysis, 28, 779-799.

Jiang, P., Haimes, Y.Y., 2004. Risk management for Leontief-based interdependent systems. Risk Analysis, 24, 1215-1229.

Jonkeren, O., Giannopoulos, G., 2014. Analysing Critical Infrastructure Failure with a Resilience Inoperability Input-Output Model. Economic Systems Research, 26, 39-59.

Kajitani, Y., Chang, S.E., Tatano, H., 2013. Economic Impacts of the 2011 Tohoku-Oki Earthquake and Tsunami. Earthquake Spectra, 29, S457-S478.

Kerschner, C., Bermejo, R., Arto, I., 2009. Petróleo y carbón: del cenit del petróleo al cenit del carbón. Ecología Política 39, Cambio Climático y Energías Renovables, 23-36 (in Spanish).

Leckcivilize, A., 2013. The Impact of Supply Chain Disruptions: Evidence from the Japanese Tsunami. Presented at the 21st International Input-Output Conference, Kitakyushu, Japan. 
Lian, C., Haimes, Y.Y., 2006. Managing the risk of terrorism to interdependent infrastructure systems through the dynamic inoperability input-output model. Systems Engineering, 9, 241-258.

Miller, R.E., Blair, P.D., 2009. Input-Output Analysis: Foundations and Extensions, 2nd ed. Cambridge University Press, Cambridge UK.

Mirza, M.M.Q., 2003. Climate change and extreme weather events: can developing countries adapt? Climate Policy, 3, 233-248.

OICA, 2012. Production Statistics. 2010 Statistics http://oica.net/category/productionstatistics/2010-statistics/

Okuyama, Y., 2004. Modeling spatial economic impacts of an earthquake: input-output approaches. Disaster Prevention and Management, 13, 297-306.

Okuyama, Y., 2010. Globalization and Localization of Disaster Impacts: An Empirical Examination. CESifo Forum, CESifo Forum 11, 56-66.

Okuyama, Y., Hewings, G.J.D., Sonis, M., 2004. Measuring Economic Impacts of Disasters: Interregional Input-Output Analysis Using Sequential Interindustry Model, in: Okuyama, D.Y., Chang, P.S.E. (Eds.), Modeling Spatial and Economic Impacts of Disasters, Advances in Spatial Science. Springer Berlin Heidelberg, pp. 77-101.

Okuyama, Y., Sahin, S., 2009. Impact Estimation of Disasters: A Global Aggregate for 1960 to 2007 (SSRN Scholarly Paper No. ID 1421704). Social Science Research Network, Rochester, NY.

Okuyama, Y., Santos, J.R., 2014. Disaster Impact and Input-Output Analysis. Economic Systems Research, 26, 1-12.

Okuyama, Y., Sonis, M., Hewings, G.J.D., 1999. Economic Impacts of an Unscheduled, Disruptive Event: A Miyazawa Multiplier Analysis, in: Hewings, P.G.J.D., Sonis, P.M., Madden, P.M., Kimura, P.Y. (Eds.), Understanding and Interpreting Economic Structure, Advances in Spatial Science. Springer Berlin Heidelberg, pp. 113-143.

Ranghieri, F., Ishiwatari, M., 2012. Learning from Megadisasters : Lessons from the Great East Japan Earthquake. World Bank, Washington DC.

Robinet, M., 2011. Japan Disaster Output Impacts Update. http://www.oesa.org/DocVault/Knowledge-Center/Archived-Docs/Japan-Earthquake-Information/IHS-JapanDisaster-Output-Impact-Update-June-10.pdf

Rose, A., Wei, D., 2013. Estimating the Economic Consequences of a Port Shutdown: The Special Role of Resilience. Economic Systems Research, 25, 212-232. 
Santos, J.R., Haimes, Y.Y., 2004. Modeling the demand reduction input-output (I-O) inoperability due to terrorism of interconnected infrastructures. Risk Analysis, 24, $1437-1451$.

Steinback, S.R., 2004. Using Ready-Made Regional Input-Output Models to Estimate Backward-Linkage Effects of Exogenous Output Shocks. The Review of Regional Studies, 34, 57-71.

van der Veen, A., Logtmeijer, C., 2005. Economic Hotspots: Visualizing Vulnerability to Flooding. Natural Hazards, 36, 65-80.

Yamano, N., Kajitani, Y., Shumuta, Y., 2007. Modeling the Regional Economic Loss of Natural Disasters: The Search for Economic Hotspots. Economic Systems Research, 19, 163 181.

Yuan, C., Liu, S., Xie, N., 2010. The impact on chinese economic growth and energy consumption of the Global Financial Crisis: An input-output analysis. Energy, 35, $1805-1812$. 
Figure 1: Multi-regional input-output table for two regions

\begin{tabular}{|c|c|c|c|c|c|c|}
\hline \multicolumn{2}{|c|}{ region } & $\mathrm{R}$ & $\mathrm{S}$ & \multirow[t]{2}{*}{$\mathrm{R}$} & \multirow[t]{2}{*}{$\mathrm{S}$} & \\
\hline & sector & 12 & 12 & & & \\
\hline $\mathrm{R}$ & $\begin{array}{l}1 \\
2\end{array}$ & $Z^{R R}$ & $Z^{R S}$ & $y^{R R}$ & $\mathbf{y}^{\mathrm{RS}}$ & $x^{R}$ \\
\hline $\mathrm{S}$ & 1 & $Z^{S R}$ & $Z^{S S}$ & $y^{S R}$ & $y^{s s}$ & $x^{S}$ \\
\hline & & $\left(w^{R}\right)^{\prime}$ & $\left(w^{S}\right)^{\prime}$ & & & \\
\hline & & $\left(x^{R}\right)^{\prime}$ & $\left(x^{S}\right)^{\prime}$ & & & \\
\hline
\end{tabular}

Figure 2. Flowchart of backward impacts calculated with the standard mixed MRIO model

\section{Region S}

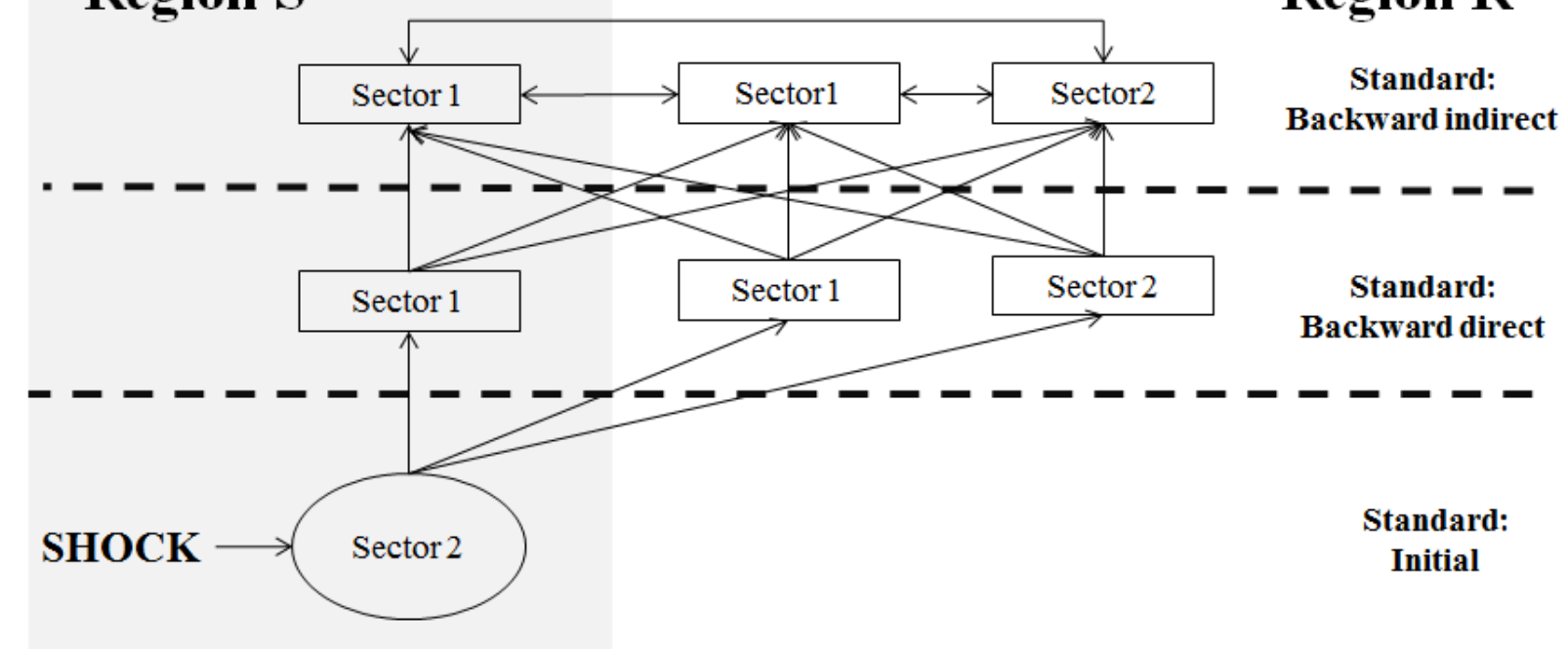

Source: own elaboration.

Note: circles denote exogenous variables; rectangles denote endogenous variables; solid arrows denote interactions explicitly captured by the model; arrowheads denote the direction of the impacts. 
Figure 3. Flowchart of impacts due to the disruption of the supply chain calculated with the mixed MRIO model with information on the first round impacts

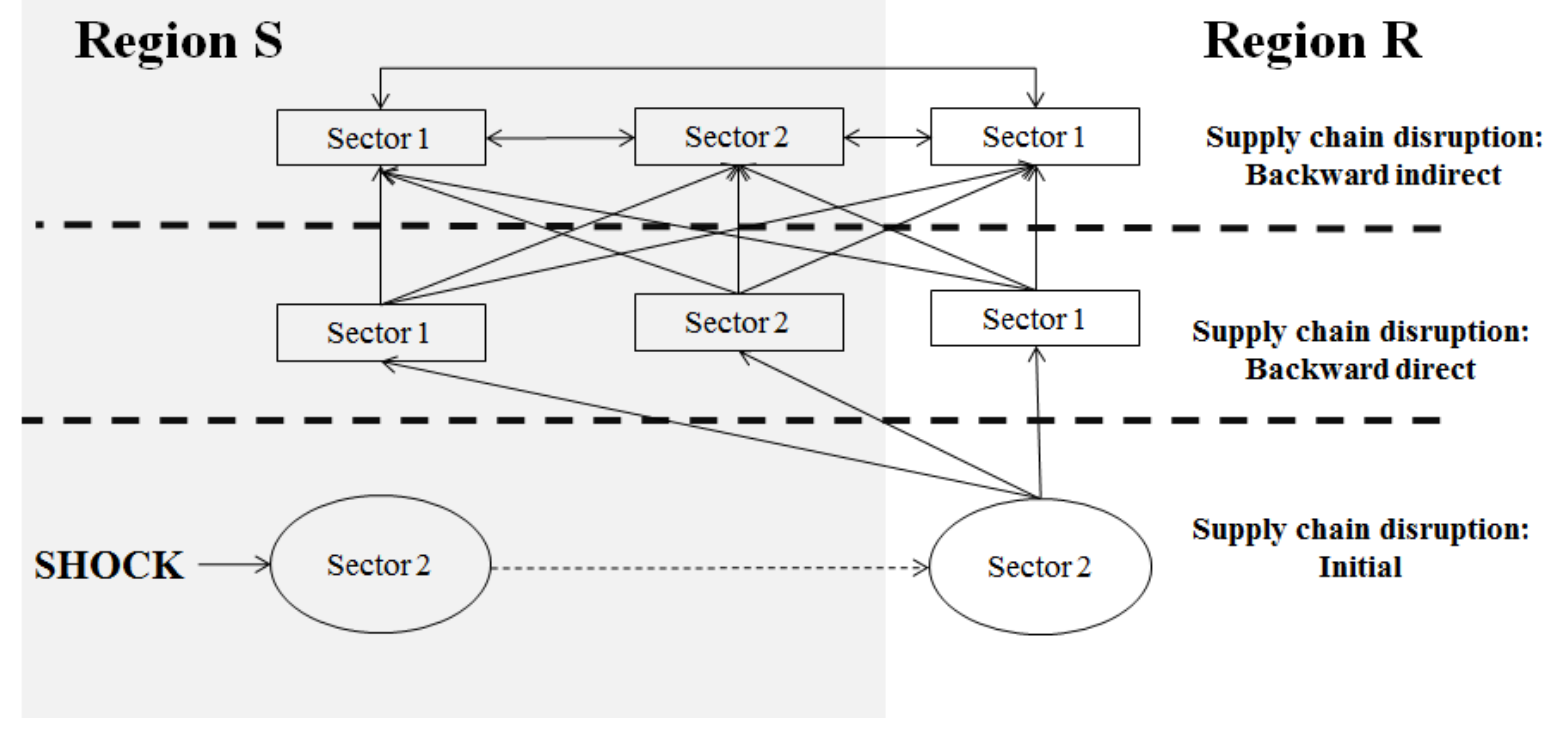

Source: own elaboration.

Note: circles denote exogenous variables; rectangles denote endogenous variables; solid arrows denote interactions explicitly captured by the model; dashed arrows denote interactions implicitly captured by the model; arrowheads denote the direction of the impacts. 
Table 1. Change in the output of the "Transport Equipment" sector by region

\begin{tabular}{|c|c|c|c|c|c|c|}
\hline & $\begin{array}{r}\text { Redu } \\
\text { in } \\
\text { producti } \\
20\end{array}$ & $\begin{array}{l}\text { tion } \\
\text { e of LV } \\
0\end{array}$ & & & & \\
\hline & $\begin{array}{l}\text { Units } \\
\text { (1) }\end{array}$ & $\begin{array}{l}\text { Number } \\
\text { Facilities } \\
\text { Affected } \\
(2) \\
\end{array}$ & $\begin{array}{c}\text { LV } \\
\text { Production, } \\
2010 \text { (units) } \\
\text { (3) } \\
\end{array}$ & $\begin{array}{c}\% \text { change } \\
\text { LV } \\
\text { production } \\
(4)=(3) /(1) \\
\end{array}$ & $\begin{array}{c}\text { Gross output } \\
\text { TEI, 2010 } \\
\text { (million US\$) } \\
(5) \\
\end{array}$ & $\begin{array}{c}\text { Change } \\
\text { Gross output } \\
\text { TEI, 2010 } \\
\text { (million US\$) } \\
(6)=(4) *(5)\end{array}$ \\
\hline Austria & 11,863 & 1 & 205,334 & $-5.78 \%$ & 18,684 & $-1,080$ \\
\hline Belgium & 3,184 & 1 & 528,996 & $-0.60 \%$ & 23,868 & -143 \\
\hline Brazil & 55,820 & 2 & $2,828,273$ & $-1.97 \%$ & 136,576 & $-2,691$ \\
\hline Canada & 105,306 & 5 & 968,860 & $-10.87 \%$ & 201,834 & $-21,939$ \\
\hline China & 284,000 & 16 & $13,897,083$ & $-2.04 \%$ & 674,956 & $-13,769$ \\
\hline France & 18,585 & 2 & $1,924,171$ & $-0.97 \%$ & 218,622 & $-2,121$ \\
\hline Germany & 5,403 & 1 & $5,552,409$ & $-0.10 \%$ & 437,252 & -437 \\
\hline Hungary & 2,404 & 1 & 208,571 & $-1.15 \%$ & 15,188 & -175 \\
\hline India & 35,355 & 5 & $2,814,584$ & $-1.26 \%$ & 101,404 & $-1,278$ \\
\hline Indonesia & 42,306 & 3 & 496,524 & $-8.52 \%$ & 50,953 & $-4,341$ \\
\hline Japan & $1,716,000$ & 41 & $8,307,382$ & $-20.66 \%$ & 507,684 & $-104,887$ \\
\hline Mexico & 24,478 & 1 & $1,390,163$ & $-1.76 \%$ & 90,241 & $-1,588$ \\
\hline Russia & 2,765 & 1 & $1,208,362$ & $-0.23 \%$ & 58,203 & -134 \\
\hline South Korea & 2,433 & 1 & $3,866,206$ & $-0.06 \%$ & 208,693 & -125 \\
\hline Spain & 15,346 & 2 & $1,913,513$ & $-0.80 \%$ & 78,740 & -630 \\
\hline Turkey & 15,124 & 2 & 603,394 & $-2.51 \%$ & 22,550 & -566 \\
\hline United Kingdom & 65,473 & 5 & $1,270,444$ & $-5.15 \%$ & 107,365 & $-5,529$ \\
\hline United States & 248,216 & 24 & $2,731,105$ & $-9.09 \%$ & 582,933 & $-52,989$ \\
\hline Rest of the World & 100,595 & 15 & $7,439,849$ & $-1.35 \%$ & 331,305 & $-4,473$ \\
\hline World total & $2,754,656$ & 129 & $58,155,223$ & $-4.74 \%$ & $4,187,594$ & $-198,492$ \\
\hline
\end{tabular}

Source: own elaboration based on Robinet (2011), OICA (2012) and WIOD.

Note: LV: Light Vehicles; TEI: Transport Equipment Industry. 
Table 2. Change in Value Added by region and impact category (million US\$)

\begin{tabular}{|c|c|c|c|c|c|c|c|c|c|}
\hline & \multirow{2}{*}{$\begin{array}{l}\text { Base } \\
\text { Value } \\
\text { Added. } \\
2010 \\
(1)\end{array}$} & \multicolumn{3}{|c|}{ Standard effect } & \multicolumn{3}{|c|}{ Supply chain disruption effect } & \multirow{2}{*}{$\begin{array}{l}\text { Total } \\
\text { Change } \\
(8)=(2) \\
+(7)\end{array}$} & \multirow{2}{*}{$\begin{array}{c}\text { Share } \\
\text { Total } \\
(90)\end{array}$} \\
\hline & & $\begin{array}{c}\text { I } \\
(2)\end{array}$ & $\begin{array}{l}\text { BD } \\
\text { (3) }\end{array}$ & $\begin{array}{l}\text { BI } \\
(4)\end{array}$ & $\begin{array}{c}\text { I } \\
(5)\end{array}$ & $\begin{array}{l}\text { BD } \\
\text { (6) }\end{array}$ & $\begin{array}{l}\text { BI } \\
\text { (7) }\end{array}$ & & \\
\hline Australia & $1,199,482$ & 0 & -43 & -479 & -480 & -502 & -693 & $-2,196$ & $1.58 \%$ \\
\hline Brazil & $1,803,334$ & 0 & -14 & -96 & -527 & -698 & -455 & $-1,791$ & $1.29 \%$ \\
\hline Canada & $1,458,647$ & 0 & -17 & -142 & $-4,521$ & $-4,573$ & -859 & $-10,112$ & $7.27 \%$ \\
\hline China & $5,931,085$ & 0 & -289 & $-1,357$ & $-2,686$ & $-2,983$ & $-3,810$ & $-11,124$ & $8.00 \%$ \\
\hline European Union & $14,677,889$ & 0 & -185 & -939 & $-2,475$ & $-3,316$ & $-3,476$ & $-10,391$ & $7.47 \%$ \\
\hline Austria & 339,119 & 0 & -7 & -29 & 0 & -44 & -91 & -172 & $0.12 \%$ \\
\hline Belgium & 421,101 & 0 & -4 & -31 & -24 & -70 & -122 & -251 & $0.18 \%$ \\
\hline Bulgaria & 38,532 & 0 & 0 & -2 & 0 & -1 & -7 & -9 & $0.01 \%$ \\
\hline Cyprus & 20,776 & 0 & 0 & 0 & 0 & 0 & -1 & -2 & $0.00 \%$ \\
\hline Czech R. & 172,005 & 0 & -3 & -13 & 0 & -20 & -50 & -86 & $0.06 \%$ \\
\hline Denmark & 268,880 & 0 & -2 & -15 & 0 & -21 & -54 & -91 & $0.07 \%$ \\
\hline Estonia & 16,538 & 0 & 0 & -1 & 0 & -1 & -3 & -6 & $0.00 \%$ \\
\hline Finland & 205,147 & 0 & -4 & -22 & 0 & -18 & -57 & -101 & $0.07 \%$ \\
\hline France & $2,346,940$ & 0 & -22 & -125 & -347 & -518 & -457 & $-1,469$ & $1.06 \%$ \\
\hline Germany & $2,992,408$ & 0 & -64 & -277 & -99 & -595 & -484 & $-1,519$ & $1.09 \%$ \\
\hline Greece & 273,987 & 0 & 0 & -6 & 0 & -3 & -16 & -25 & $0.02 \%$ \\
\hline Hungary & 110,628 & 0 & -2 & -10 & -36 & -32 & -25 & -105 & $0.08 \%$ \\
\hline Ireland & 188,777 & 0 & -3 & -21 & 0 & -29 & -75 & -128 & $0.09 \%$ \\
\hline Italy & $1,841,362$ & 0 & -13 & -82 & 0 & -132 & -376 & -603 & $0.43 \%$ \\
\hline Latvia & 21,699 & 0 & 0 & -1 & 0 & 0 & -3 & -4 & $0.00 \%$ \\
\hline Lithuania & 32,775 & 0 & 0 & -1 & 0 & -1 & -4 & -6 & $0.00 \%$ \\
\hline Luxembourg & 49,162 & 0 & 0 & -5 & 0 & -4 & -14 & -23 & $0.02 \%$ \\
\hline Malta & 7,185 & 0 & 0 & -1 & 0 & -1 & -2 & -4 & $0.00 \%$ \\
\hline Netherlands & 698,412 & 0 & -11 & -46 & 0 & -83 & -193 & -332 & $0.24 \%$ \\
\hline Poland & $\begin{array}{l}410,889 \\
\end{array}$ & 0 & -6 & -27 & 0 & -43 & -116 & -192 & $0.14 \%$ \\
\hline Portugal & 200,292 & 0 & 0 & -5 & 0 & -10 & -27 & -42 & $0.03 \%$ \\
\hline Romania & 147,328 & 0 & -1 & -6 & 0 & -8 & -21 & -35 & $0.03 \%$ \\
\hline Slovakia & 79,580 & 0 & -1 & -5 & 0 & -5 & -19 & -29 & $0.02 \%$ \\
\hline Slovenia & 40,981 & 0 & 0 & -2 & 0 & -3 & -8 & -13 & $0.01 \%$ \\
\hline Spain & $1,290,057$ & 0 & -6 & -45 & -126 & -192 & -201 & -569 & $0.41 \%$ \\
\hline Sweden & 403,043 & 0 & -5 & -38 & 0 & -52 & -144 & -238 & $0.17 \%$ \\
\hline United Kingdom & $2,060,286$ & 0 & -31 & -122 & $-1,844$ & $-1,432$ & -907 & $-4,336$ & $3.12 \%$ \\
\hline India & $1,564,494$ & 0 & -13 & -86 & -307 & -372 & -354 & $-1,132$ & $0.81 \%$ \\
\hline Indonesia & 708,944 & 0 & -54 & -286 & $-1,760$ & -947 & 190 & $-2,857$ & $2.05 \%$ \\
\hline Japan & $5,370,277$ & $-24,964$ & $-23,281$ & $-4,546$ & 0 & -496 & $-1,599$ & $-54,886$ & $39.46 \%$ \\
\hline Mexico & 991,003 & 0 & -14 & -59 & -481 & -855 & -152 & $-1,560$ & $1.12 \%$ \\
\hline Russia & $1,296,437$ & 0 & -12 & -250 & -25 & -48 & -305 & -640 & $0.46 \%$ \\
\hline South Korea & 912,259 & 0 & -123 & -368 & -28 & -181 & -271 & -972 & $0.70 \%$ \\
\hline Taiwan & 410,200 & 0 & -40 & -184 & 0 & -93 & -331 & -647 & $0.47 \%$ \\
\hline Turkey & 640,039 & 0 & -3 & -20 & -147 & -126 & -127 & -422 & $0.30 \%$ \\
\hline United States & $14,525,130$ & 0 & -206 & -834 & $-11,094$ & $-14,860$ & $-8,090$ & $-35,084$ & $25.22 \%$ \\
\hline Rest of World & $8,859,798$ & 0 & -270 & $-2,145$ & 0 & -503 & $-2,354$ & $-5,272$ & $3.79 \%$ \\
\hline Total & $60,349,018$ & $-24,964$ & $-24,565$ & $-11,789$ & $-24,530$ & $-30,551$ & $-22,687$ & $-139,086$ & $100.00 \%$ \\
\hline
\end{tabular}

Source: own elaboration.

Note: I: initial; BD: backward direct; BI: backward indirect. The standard effect includes the indirect impact in the Japanese TEI industry and the resulting from the reduction in its demand for intermediates. The supply chain disruption effect include the impact in the non-Japanese TEI affected by the disruption in the intermediate deliveries of the Japanese TEI, and the subsequent cascading effects in all the other sectors supplying components to the non-Japanese TEI. 
Table 3. Change in Global Value Added by sector (million US\$)

\begin{tabular}{|c|c|c|c|c|}
\hline Sector & $\begin{array}{c}\text { Base } \\
\text { Value } \\
\text { Added, } \\
2010 \\
(1)\end{array}$ & $\begin{array}{c}\text { Total } \\
\text { Change } \\
\text { (2) }\end{array}$ & $\begin{array}{c}\text { Total } \\
\text { Change } \\
\text { (3) }\end{array}$ & $\begin{array}{c}\text { Share } \\
\text { Total } \\
\text { (4) }\end{array}$ \\
\hline Transport Equipment & 919,281 & $-50,918$ & $-5.54 \%$ & $36.61 \%$ \\
\hline Renting of M\&Eq and Other Business Activities & $5,536,094$ & $-14,010$ & $-0.25 \%$ & $10.07 \%$ \\
\hline Basic Metals and Fabricated Metal & $1,397,059$ & $-11,437$ & $-0.82 \%$ & $8.22 \%$ \\
\hline $\begin{array}{l}\text { Wholesale Trade and Commission Trade, Except of Motor Vehicles and } \\
\text { Motorcycles }\end{array}$ & $3,721,066$ & $-9,843$ & $-0.26 \%$ & $7.08 \%$ \\
\hline Financial Intermediation & $3,969,288$ & $-6,124$ & $-0.15 \%$ & $4.40 \%$ \\
\hline Mining and Quarrying & $2,769,023$ & $-5,356$ & $-0.19 \%$ & $3.85 \%$ \\
\hline Electrical and Optical Equipment & $1,342,103$ & $-5,277$ & $-0.39 \%$ & $3.79 \%$ \\
\hline Rubber and Plastics & 405,816 & $-3,056$ & $-0.75 \%$ & $2.20 \%$ \\
\hline Inland Transport & $1,583,107$ & $-3,005$ & $-0.19 \%$ & $2.16 \%$ \\
\hline Chemicals and Chemical Products & $1,048,789$ & $-2,937$ & $-0.28 \%$ & $2.11 \%$ \\
\hline $\begin{array}{l}\text { Retail Trade, Except of Motor Vehicles and Motorcycles; Repair of Household } \\
\text { Goods }\end{array}$ & $2,952,799$ & $-2,925$ & $-0.10 \%$ & $2.10 \%$ \\
\hline Electricity, Gas and Water Supply & $1,320,998$ & $-2,910$ & $-0.22 \%$ & $2.09 \%$ \\
\hline Machinery, Nec & 865,215 & $-2,663$ & $-0.31 \%$ & $1.91 \%$ \\
\hline Real Estate Activities & $5,656,456$ & $-2,422$ & $-0.04 \%$ & $1.74 \%$ \\
\hline Other Community, Social and Personal Services & $2,128,171$ & $-2,382$ & $-0.11 \%$ & $1.71 \%$ \\
\hline Post and Telecommunications & $1,378,709$ & $-1,650$ & $-0.12 \%$ & $1.19 \%$ \\
\hline Pulp, Paper, Paper, Printing and Publishing & 695,923 & $-1,452$ & $-0.21 \%$ & $1.04 \%$ \\
\hline Hotels and Restaurants & $1,535,419$ & $-1,236$ & $-0.08 \%$ & $0.89 \%$ \\
\hline Other Supporting and Auxiliary Transport Activities; Activities of Travel Agencies & 689,614 & $-1,152$ & $-0.17 \%$ & $0.83 \%$ \\
\hline Coke, Refined Petroleum and Nuclear Fuel & 542,546 & $-1,046$ & $-0.19 \%$ & $0.75 \%$ \\
\hline Other Non-Metallic Mineral & 420,032 & -998 & $-0.24 \%$ & $0.72 \%$ \\
\hline $\begin{array}{l}\text { Sale, Maintenance and Repair of Motor Vehicles and Motorcycles; Retail Sale of } \\
\text { Fuel }\end{array}$ & 628,835 & -931 & $-0.15 \%$ & $0.67 \%$ \\
\hline Construction & $3,327,934$ & -838 & $-0.03 \%$ & $0.60 \%$ \\
\hline Agriculture, Hunting, Forestry and Fishing & $2,543,128$ & -832 & $-0.03 \%$ & $0.60 \%$ \\
\hline Water Transport & 239,806 & -547 & $-0.23 \%$ & $0.39 \%$ \\
\hline Textiles and Textile Products & 467,474 & -545 & $-0.12 \%$ & $0.39 \%$ \\
\hline Food, Beverages and Tobacco & $1,441,129$ & -511 & $-0.04 \%$ & $0.37 \%$ \\
\hline Public Admin and Defence; Compulsory Social Security & $4,637,264$ & -497 & $-0.01 \%$ & $0.36 \%$ \\
\hline Manufacturing, Nec; Recycling & 309,346 & -480 & $-0.16 \%$ & $0.35 \%$ \\
\hline Wood and Products of Wood and Cork & 205,928 & -388 & $-0.19 \%$ & $0.28 \%$ \\
\hline Air Transport & 196,637 & -210 & $-0.11 \%$ & $0.15 \%$ \\
\hline Education & $2,098,457$ & -201 & $-0.01 \%$ & $0.14 \%$ \\
\hline Health and Social Work & $3,188,723$ & -170 & $-0.01 \%$ & $0.12 \%$ \\
\hline Leather, Leather and Footwear & 82,308 & -119 & $-0.14 \%$ & $0.09 \%$ \\
\hline \multirow[t]{2}{*}{ Private Households with Employed Persons } & 104,541 & -17 & $-0.02 \%$ & $0.01 \%$ \\
\hline & $60,349,018$ & $-139,086$ & $-0.23 \%$ & $100.00 \%$ \\
\hline
\end{tabular}

Source: own elaboration. 